\title{
Segurança operacional em barragens de pequeno porte
}

Operational safety in small dams

\author{
Marcos Delgado Gontijo ${ }^{1, *}$ \\ ${ }^{1}$ Departamento Nacional de Produção Mineral, DNPM, Brasil. \\ *marcosdgontijo@yahoo.com.br
}

\begin{abstract}
Resumo
A busca e estudos permanentes de alternativas de operação validadas por especialistas são importantes para corrigir problemas pontuais e aumentar a confiabilidade e a conservação das barragens. Algumas ações preventivas em barragens de pequeno porte, permitidas nas especificações de projetos, podem aumentar a segurança e a eficiência das mesmas, em especial as barragens tipo terra e enrocamento, construídas a partir de terra e materiais estéreis de mina ou materiais de empréstimos adequados a sua construção. Dentre as ações identificadas neste trabalho, está o uso das chamadas "praias de rejeitos", das leiras e das barragens de clarificação de água e segurança.
\end{abstract}

Palavras-chave: Barragem, Leira de Proteção, Praia de Rejeitos.

\footnotetext{
The search for and permanent studies of alternatives operational, validated by specialists, are important to correct specific problems sand increase the reliability and conservation of dams. Some preventive actions in small dams, allowed in project specifications, can increase their safety and efficiency, especially ground and rock barrages constructed from land and sterile mine materials or its construction. Among the actions identified in this work are the use of so-called "tailing beaches, "the ground elevation and water clarification and safety of dams.
}

Keywords: Dam, Protection Berm, Tailing Beach. 


\section{INTRODUÇÃO}

Os materiais de descarte, classificados como rejeitos finos, podem ser depositados em barragens de lamas, especialmente projetadas para esse fim. Estes materiais, quando dispostos indevidamente, podem ser carreados e assorear rios e nascentes, além de promover danos diversos. Também podem causar acidentes com riscos às vidas humanas, fauna e flora, bem como causar contaminação química dos efluentes por características dos rejeitos minerados e aditivos, eventualmente adicionados aos mesmos. Durante e após a disposição dos rejeitos, é necessário um controle permanente e a observância das recomendações e manuais de projeto.

O contato direto da lâmina d'água com o barramento deve ser monitorado de perto, de modo a evitar danos e acidentes. As chamadas praias de rejeitos são zonas de transição, planejadas e devidamente especificadas, que criam uma interface entre o material estrutural do barramento e a lâmina de água ou polpa de minério (RESENDE, 2012). Normalmente, as praias são usadas nas barragens construídas a partir de alteamentos com rejeitos adensados a montante, em linha de centro e, ocasionalmente, a jusante, mas também podem ser um fator adicional de segurança para barragens convencionais de terra e enrocamento.

O controle da drenagem sobre o barramento é importante, especialmente em épocas de chuva e regiões com elevados índices pluviométricos. A água não deve escorrer livremente, especialmente para o lado externo do barramento, provocando erosões que podem progredir rapidamente. Uma alternativa é a construção de leiras de proteção, que se configura em um fator de segurança para veículos, e que podem agir na contenção dos fluxos e escoamento para os locais específicos de drenagem da barragem.

As barragens de rejeito têm a função principal de armazenar os rejeitos e, como tais, devem drenar as águas da melhor forma possível. No entanto, a água descartada, em muitos casos, não está em condições de retorno ao meio ambiente ou condições de reutilização, necessitando de um segundo estágio ou local para clarificação e estocagem. Essa barragem complementar pode ser dimensionada para servir de barragem de segurança à barragem principal (de adensamento e estocagem do rejeito).

\section{OBJETIVOS E RELEVÂNCIA}

Objetiva-se, neste trabalho, apresentar um estudo de alternativas para melhorar a segurança operacional dos rejeitos dispostos em barragens convencionais de enrocamento, construídas com utilização de estéreis ou materiais provenientes de áreas de empréstimos.

Os estudos e critérios operacionais das barragens devem ser rigorosos e contínuos, especialmente porque os problemas podem gerar danos ao meio ambiente e aos seres humanos, como no caso recente do rompimento da barragem da SAMARCO em Mariana. Devem ser criadas alternativas que vão desde a redução dos rejeitos gerados, passando pelo melhor adensamento dos mesmos, por sistemas que permitam maiores estabilidades dos materiais estocados e das estruturas construtivas, bem como sistemas eficientes de drenagem e reaproveitamento dos recursos hídricos. 


\section{REVISÃO DA LITERATURA}

O processo utilizado em minas a céu aberto envolve: decapeamento da jazida, perfuração, desmonte e operações de transporte. Após a extração, os minérios são levados às unidades de beneficiamento para adequação de sua qualidade. Na lavra são, também, extraídos os materiais estéreis e no beneficiamento os rejeitos. Os rejeitos finos, normalmente, são depositados em barragens de rejeitos (MACHADO, 2007). A Figura 1 apresenta as atividades desenvolvidas na mineração de bauxita: operações de mina, beneficiamento e disposições de rejeitos.

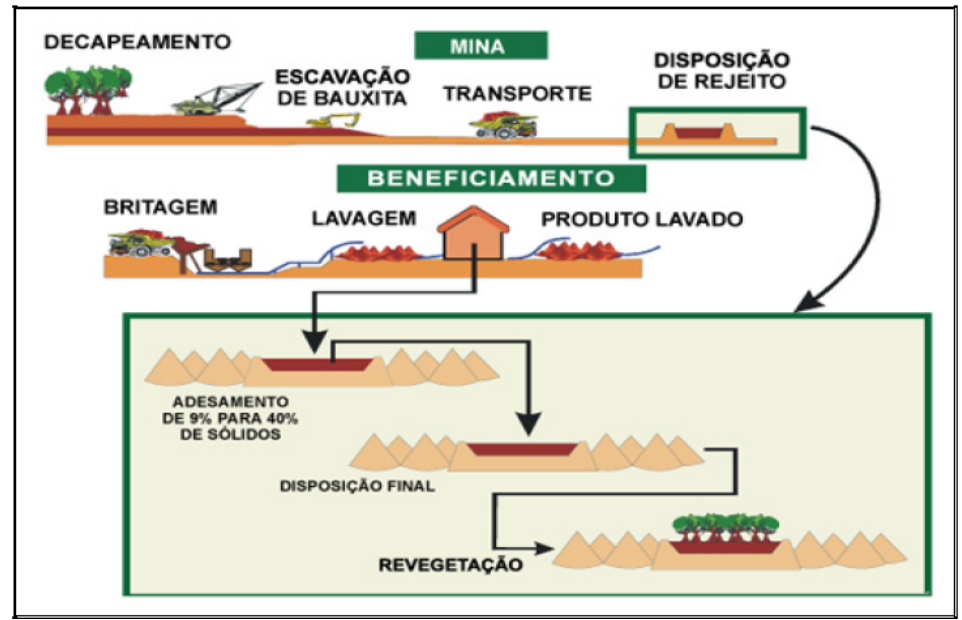

Figura 1 - Atividades de uma mineração.

Fonte: Machado (2007)

Nas últimas décadas, o rigor das exigências e legislações ambientais, relacionadas principalmente ao controle de qualidade do efluente líquido proveniente do beneficiamento mineral e à segurança global das barragens de contenção de rejeitos, tem implicado a adoção de projetos e procedimentos mais seguros (FILHO, 2004).

Para evitar o contato entre a parte estrutural da barragem com a lâmina d'água, são preservadas áreas de proteção, chamadas "praias de rejeitos". Ou seja, a praia é a área do depósito de rejeitos, próxima ao barramento, onde é disposto parte do rejeito, geralmente a fração mais grosseira.

A seguir, na Figura 2 (a) e 2 (b), tem-se fotos de exemplos de barragens, mostrando as praias de rejeitos, eixos, lagoa de decantação e aspectos gerais. 


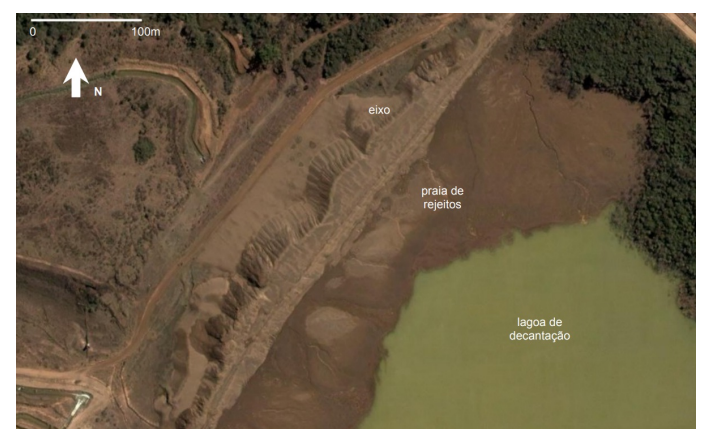

(a) Barragem da B5 - Bunge Fertilizantes, Araxá/MG.

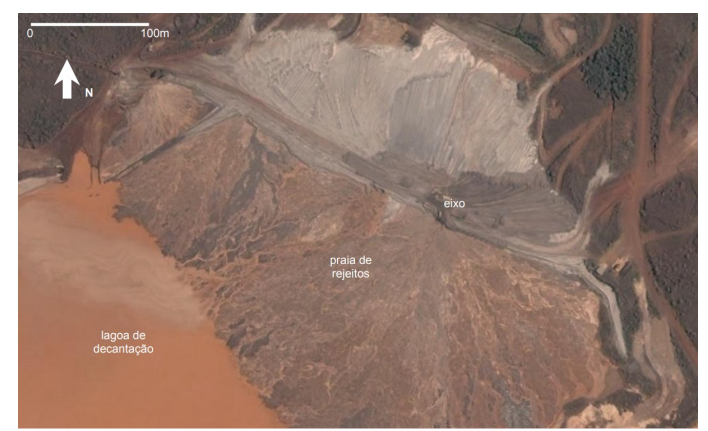

(b) Barragem Doutor - Vale, Mariana/MG.

Figura 2 - Barragens com praias de rejeitos.

Fonte: D'Agostino (2008).

Normalmente, o estabelecimento da praia de rejeitos está associado ao método de alteamento e disposição de rejeitos adensados a montante e por linha de centro. No entanto, além dos motivos de segurança, como a altura livre de projeto, mesmo para o método de construção a jusante, pode ser prevista a implantação de praia, como segurança adicional para barragens de rejeitos (Conforme apontado por Beirigo (2005)).

A Figura 3 apresenta ilustrações de sistemas prevendo a praia de rejeitos, sem e com dreno interno ao barramento.
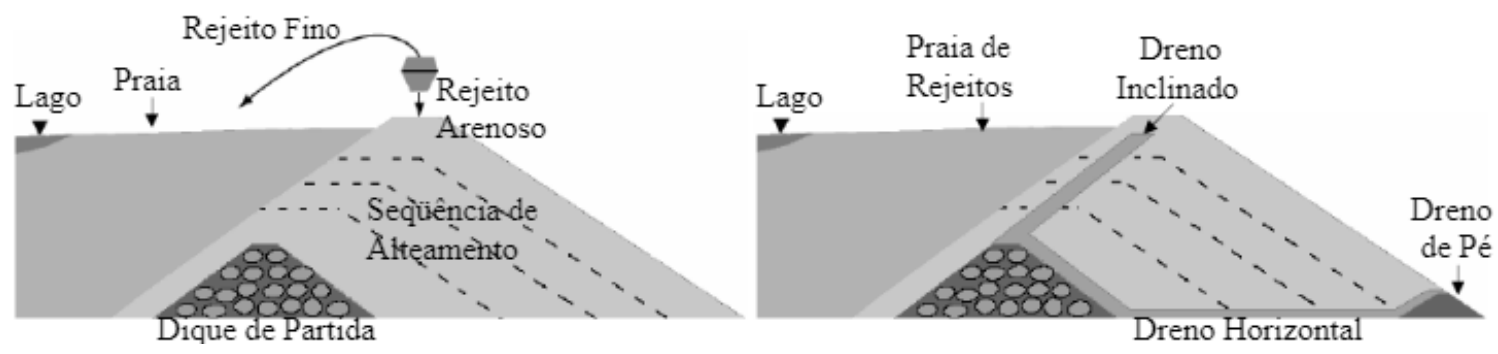

Figura 3 - Alteamento a Jusante.

Fonte: Rowatt (2001), modificado por Beirigo (2005).

Conforme Figura 3, tem-se as seguintes alternativas construtivas de uma barragem:

a) Sequência executiva;

b) Sistema com drenagem e filtração interna.

Para barragens convencionais de enrocamento, também pode ser previsto o controle por praia de rejeitos, conforme Figura 4 a seguir. 


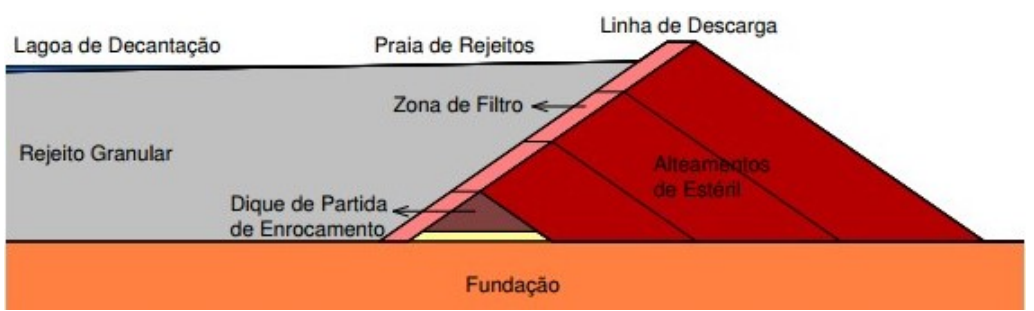

Figura 4 - Barragem convencional (terra e enrocamento) e com estéril.

Fonte: Filho (2004).

\subsection{Leiras de proteção}

As leiras, bermas estabilizantes ou bermas de proteção, são elementos de segurança que têm a função principal de evitar que os veículos que operam na estrada saiam da pista, além de servirem como elemento auxiliar no funcionamento eficaz do sistema de drenagem superficial (FILHO, 2011). São localizadas nas margens das estradas da mineração e, segundo a NR-22, devem ter altura correspondente à metade do diâmetro da roda do maior caminhão que trafegue pela estrada (REIS, 2014). A Figura 5 demonstra a configuração usual de leiras de proteção.

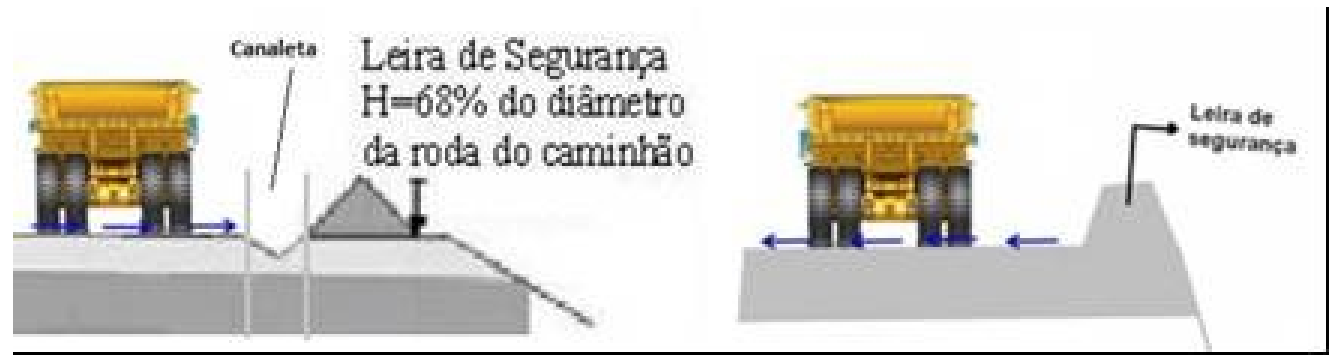

Figura 5 - Leira de proteção e dreno de pista.

Fonte: Baseado em Filho (2011).

A geometria típica das leiras de proteção geralmente é trapezoidal ou triangular. Em estradas de mina, as leiras são relativamente contínuas, com certos espaçamentos, planejados para escoamento da água de drenagem (MACHADO, 2007).

\subsection{Barragem de água}

Para armazenamento e clarificação da água proveniente da barragem de rejeitos, a barragem de água, construída a jusante, pode receber contribuições das águas e sedimentos de drenagem pluviais, águas de controles do rebaixamento do lençol freático nas cavas e outras. As barragens de rejeitos também podem, operacionalmente, serem subdivididas em setores, de espessamento e clarificação, por exemplo, podendo a subdivisão ser um barramento feito por rejeitos adensados (GONTIJO et al., 2011). Pode-se ver na Figura 6 uma barragem com dois setores. 

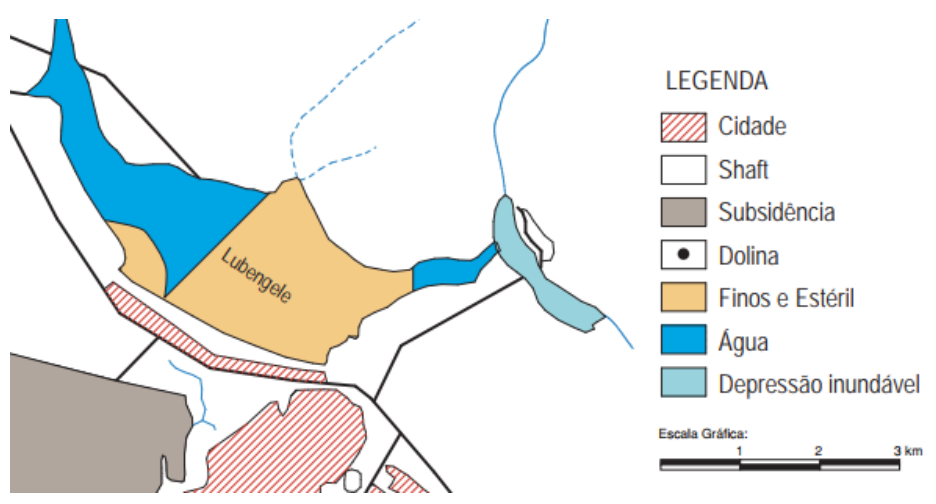

Figura 6 - Barragem com subdivisão (parte com finos e parte com água). Fonte: Adaptado de Lubenguele e Kakosa na mina Konkola (FRASA, 1993).

\section{METODOLOGIA}

O trabalho consistiu em verificação dos sistemas de operação e segurança de barragens, consideradas de pequeno porte, tendo as seguintes etapas:

- Estudo bibliográfico de alternativas existentes;

- Levantamento em campo de barragens de rejeitos e controles;

- Estudo de soluções e técnicas recomendadas.

Este trabalho tem por referência estudos desenvolvidos pelo DNPM (em 2011), em conjunto com empresas do setor, contemplando análise geotécnica, riscos e prevenções em barragens de vários contextos. No presente tema, foram verificadas e analisadas barragens de rejeitos, do tipo enrocamento, em empresas de mineração de ouro, localizadas no Estado do Mato Grosso (MT). As alternativas apresentadas, no entanto, podem adequar-se a vários tipos e portes de barragens e minérios, como para lamas de minério de ferro, desde que previstas nos projetos construtivos ou adequadamente planejadas.

\section{RESULTADOS E DISCUSSÕES}

Para assegurar as condições de estabilidade das barragens de enrocamento, consideradas de pequeno porte, devem-se estabelecer padrões mínimos de controle, de modo a:

- Reduzir possibilidade de acidentes;

- Proteção da população e do meio ambiente.

Foram verificados serviços de manutenções corretivas e preventivas, nos seguintes aspectos de segurança:

1. Construção da saia do barramento mais alongada, se possível formando praia na parte interna e o melhor ângulo de repouso externo; 
2. Monitoramento contínuo de surgências e infiltrações na base da barragem, construir drenos superficiais para evitar danos da água de chuva;

3. Adoção de sistema de drenagem, da água de chuva sobre o barramento, fazendo-a fluir para sistema de drenagem própria da barragem - com construção de leiras laterais;

4. Construção e monitoramento de reservatórios de clarificação das águas da barragem principal de rejeitos, dimensionadas preferencialmente para servirem como barragem de proteção.

Podem-se visualizar, na Figura 7 a seguir, as seguintes condições verificadas:

\section{1) Praias de rejeito}
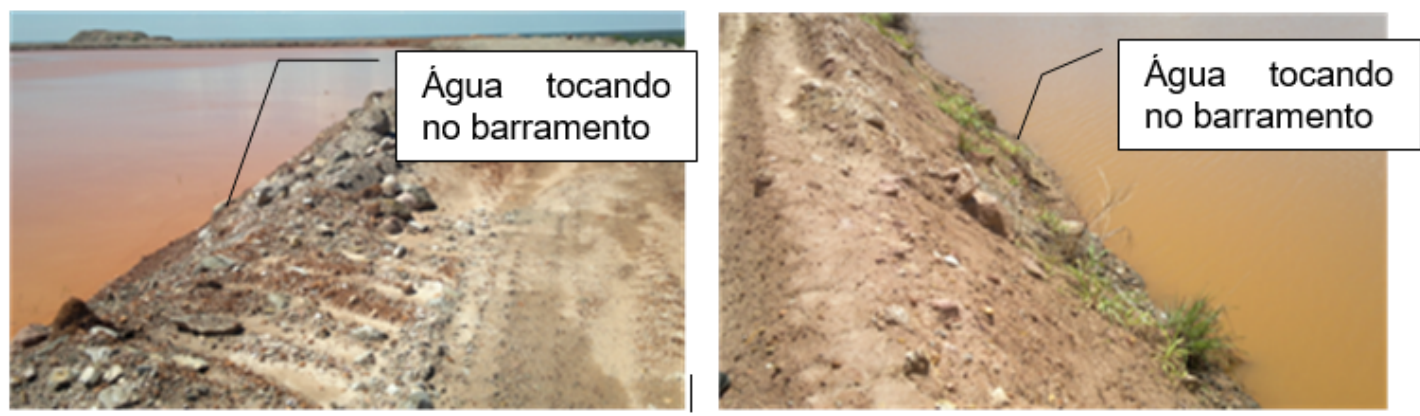

Figura 7 - Água tocando no barramento em condições normais.

Fonte: Próprio Autor (2017).

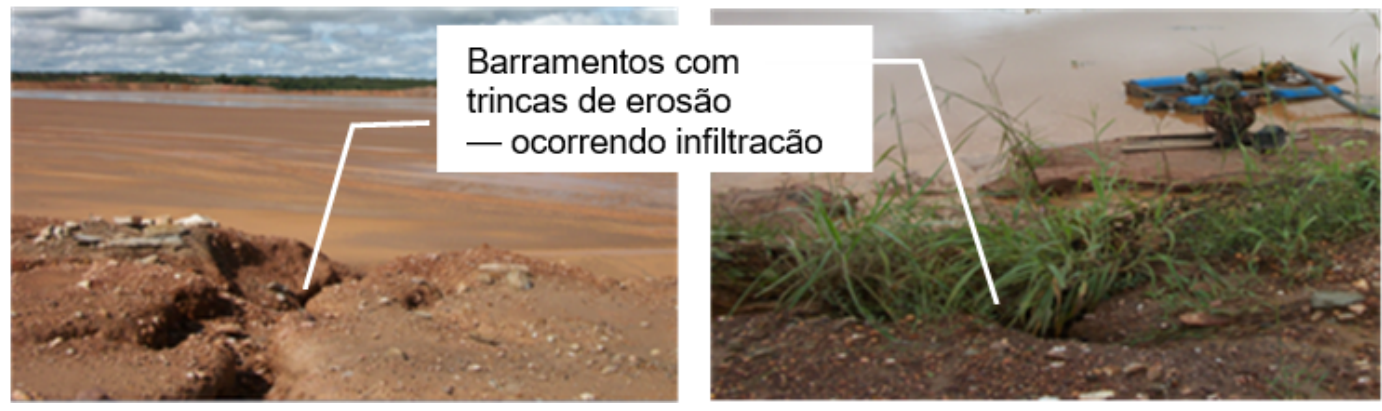

Figura 8 - Água tocando no barramento com problemas.

Fonte: Próprio Autor (2017).

A construção de saias alongadas, em forma de praias, pode ser obtida pela construção, ou por adição de materiais durante a operação. De forma especial, podem ser construídas em lados críticos dos barramentos. A Figura 9, a seguir, exibe as praias das barragens de rejeitos. 


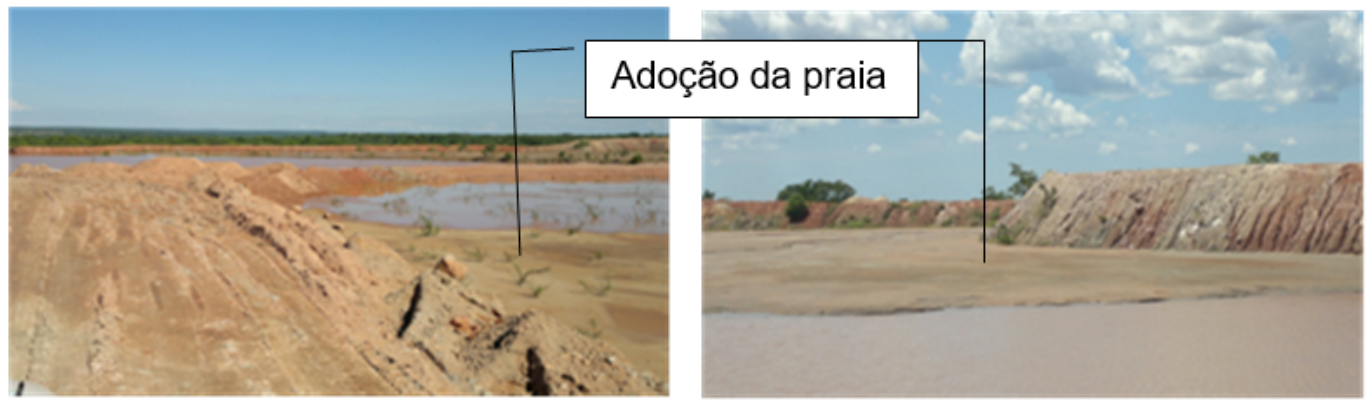

Figura 9 - "Praias" de proteção dos taludes.

Fonte: Próprio Autor (2017).

A seguir, são listados, na Figura 10, vários componentes de uma barragem teórica, podendo ser necessários os elementos apontados.

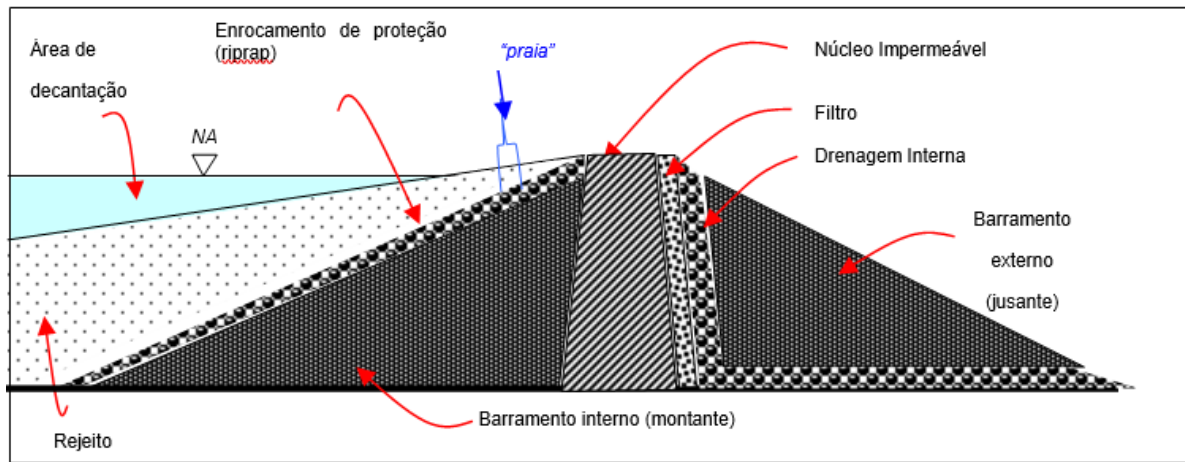

Figura 10 - Ilustração de componentes de uma barragem de rejeitos.

Fonte: Próprio Autor (2017).

\section{2) Leiras para proteção e drenagem}

Leiras são construídas sobre as cristas, nos lados externos e internos da bancada do barramento, especialmente nas áreas onde ocorre trânsito de veículos. Entretanto, sua construção pode ser um procedimento em auxílio ao sistema de drenagem, conforme Figuras 11 e 12 , a seguir:
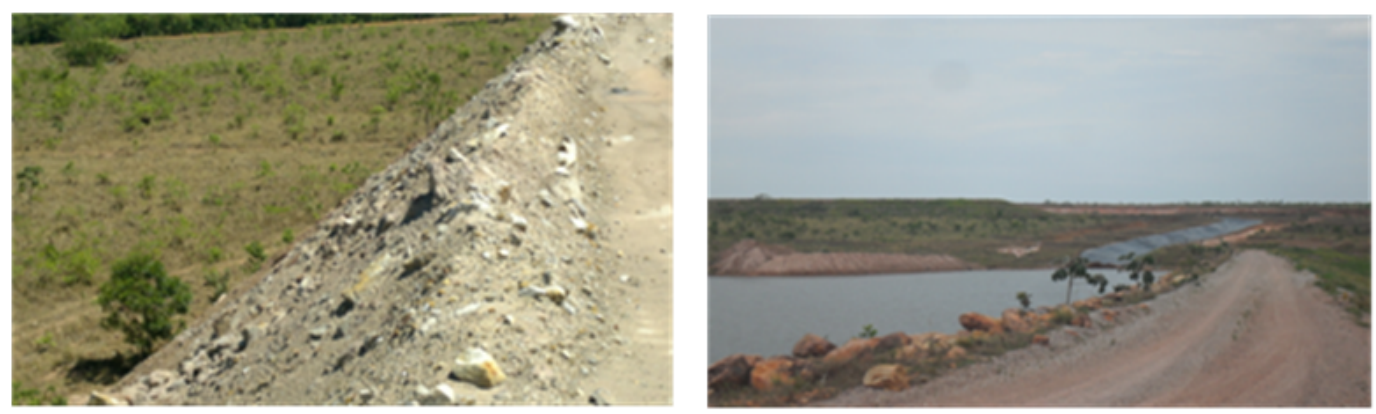

Figura 11 - Leiras sobre barramento: face externa e face interna.

Fonte: Próprio Autor (2017). 


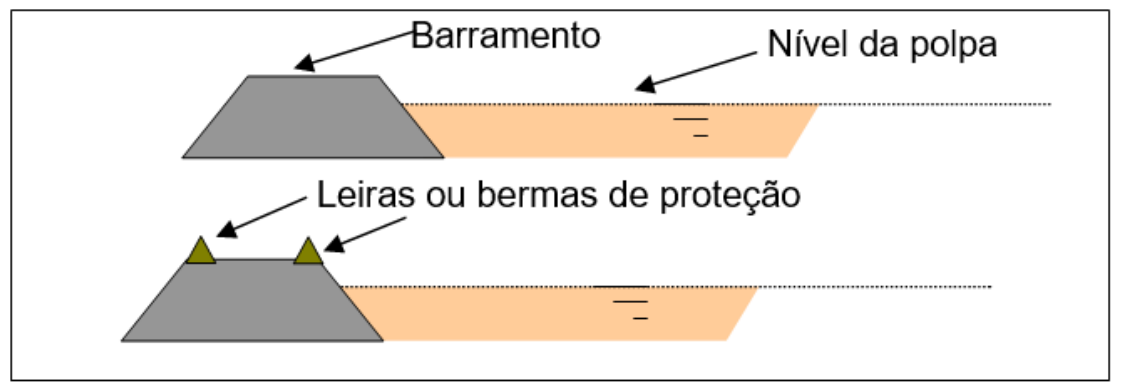

Figura 12 - Desenho ilustrativo.

Fonte: Próprio Autor (2017).

\section{3) Barragem de proteção e armazenamento de água}

Na Figura 13 temos a visualização de uma barragem dupla, sendo uma de contenção de sólidos e outra para a clarificação da água:
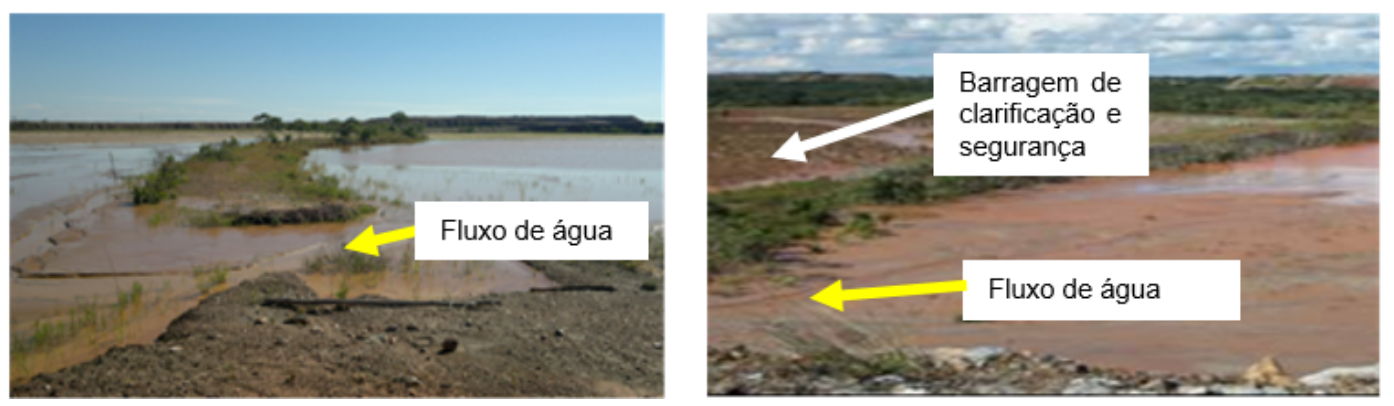

Figura 13 - Barragem dupla: adensamento e clarificação e segurança.

Fonte: Próprio Autor (2017).

Trata-se de sistema composto por duas barragens: uma barragem para decantação e outra, em sequência, para estocagem e clareamento da água, eventualmente servindo como barragem de segurança.

A Figura 14 exibe a disposição das bacias:

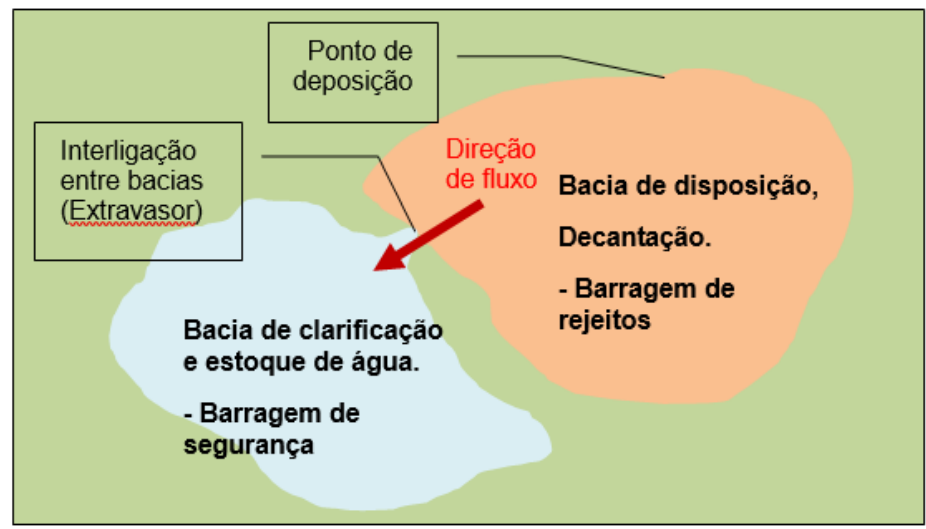

Figura 14 - Barragem para adensamento de rejeitos e barragem de água.

Fonte: Próprio Autor (2017). 


\section{CONCLUSÕES}

A segurança e eficiência das barragens é uma busca contínua e passa, dentre muitas ações, por:

- Construção de projetos adequados e sustentáveis;

- Manutenção constante e operação criteriosa;

- Melhorias e adequações contínuas, assistidas por especialistas e de acordo com as especificações de projeto;

- Manter o sistema de drenagem superficial adequadamente conservado, com uso de leiras e canaletas que assegurem o dreno fora das faces do barramento;

- Evitar o contato direto da lâmina d'água com as partes estruturais dos barramentos, se possível com saias alongadas ou praias;

- Construção de barragem de retenção, clarificação e reaproveitamento das águas drenadas, e projetar as mesmas para servirem como barragem de segurança das barragens principais.

\section{REFERÊNCIAS BIBLIOGRÁFICAS}

BEIRIGO, E. A. Comportamento filtro-drenante de geotêxteis em barragens de rejeitos de mineração. Dissertação (Mestrado em Geotecnia) - Universidade de Brasília, Brasília - DF, 2005. Disponível em: <https://www.researchgate.net/publication/3897695 2_Comportamento_filtro-drenante_de_geotexteis_em_barragens_de_rejeitos_de_min eracao >. Acesso em: 10 de nov. 2017.

D'AGOSTINO, L. F. Praias de barragens de rejeitos de mineração: características e análise da sedimentação. 2008. Tese (Doutorado) — USP, São Paulo - SP, 2008. Disponível em: <http://www.teses.usp.br/teses/disponiveis/3/3134/tde-13082008-132420/publ ico/Tese_LuizFernandoDAgostino_Praias_de_barragens_de_rejeitos_de_mineracao.pdf $>$. Acesso em: 10 de nov. 2017.

GONTIJO, M.D; FIGUEIREDO, E. M.; AMORIM M. C. Levantamento de problemas geotécnicos de barragens e descarte de resíduos dos garimpos de Poconé - MT. AÇÃO: DIFUSÃO DE TECNOLOGIA E EXTENSIONISMO MINERAL. Departamento Nacional de Produção Mineral (DNPM). Brasília - DF, 2011.

FRASA INGENIEROS CONSULTORES, S. L. Quantification of Konkola Mine Water Inflow by Source. Madrid, 1993. ZCCM Internal Report.

FILHO, L. H. A. Avaliação do comportamento geotécnico de barragens de rejeitos de minério de ferro através de ensaios de piezocone. Dissertação (Mestrado) UFOP, Ouro Preto - MG, 2004. Disponível em: < http://livros01.livrosgratis.com.br/cp103 082.pdf >. Acesso em: 8 de nov. 2017. 
FILHO, W. D. C. Proposta de tecnologias construtivas de sistema viário aplicado a minerações de ferro. Dissertação (Mestrado) - UFOP, Ouro Preto - MG, 2011. Disponível em: <http://www.nugeo.com.br/uploads/nugeo_2014/teses/arquivos/walter. pdf $>$. Acesso em: 7 de nov. 2017.

MACHADO, W. G. F. Monitoramento de barragens de contenção de rejeitos da mineração. Dissertação (Mestrado) - Escola Politécnica da Universidade de São Paulo, São Paulo - SP, 2007.

REIS, M. S. Classificação e diagnóstico das estradas de mina de lavra a céu aberto de minério de ferro dentro do quadrilátero ferrífero. Dissertação (Mestrado) — UFOP, Ouro Preto - MG, 2014. Disponível em: <http://www.repositorio.ufop.br/bitstrea m/123456789/4123/1/DISSERTA\%C3\%87\%C3\%83O_Classifica\%C3\%A7\%C3\%A3oDiag n\%C3\%B3sticoEstradas.pdf >. Acesso em: 13 de nov. 2017.

RESENDE, L. R. M. Capacidade de suporte de praias de rejeitos granulares de mineração e construção de aterros compactados. Dissertação (Mestrado) - UFOP, Ouro Preto - MG, 2012. Disponível em: <http://www.repositorio.ufop.br/bitstream/1234 56789/3034/1/DISSERTA\%C3\%87\%C3\%83O_CapacidadeSuportePraias.PDF > . Acesso em: 9 de ago. 2017.

ROWATT, G. C. Facultative matters: an introduction to tailings dams risks. General Cologne Re, Toronto - Canadá, p. 6 - 9, 2001. 